\title{
Control of quantity of prepackages: New statistical multistep sampling procedure
}

\author{
Hans-Peter Vaterlaus ${ }^{1, a}, \mathrm{Xi} \mathrm{Li}^{1}$ \\ ${ }^{1}$ Federal Institute of Metrology METAS, Lindenweg 50, 3003 Bern-Wabern
}

\begin{abstract}
Résumé. Le contrôle de la quantité exacte de produit dans les préemballages est important pour le commerce équitable, le maintien de marchés compétitifs et la protection des consommateurs contre le sous-remplissage des préemballages. Dans de nombreux pays, les autorités gouvernementales contrôlent les emballeurs ou exercent une surveillance du marché afin d'assurer le respect des exigences métrologiques concernant la quantité de produit dans les préemballages. La recommandation OIML R 87 est actuellement en cours de révision. Celle-ci prévoit une nouvelle procédure d'échantillonnage statistique en plusieurs étapes pour le contrôle statistique des préemballages. Le but de cette procédure étant de diminuer les charges des emballeurs, moins d'échantillons seront contrôlés, en particulier s'agissant de préemballages non critiques. En outre, cette nouvelle procédure permettra aux inspecteurs de gagner du temps et de l'argent, étant donné qu'il faudra ouvrir et détruire moins de préemballages lors des contrôles.
\end{abstract}

\section{Introduction}

Prepackages are defined as items consisting of a product and its packing material made up before being offered for sale and in which the quantity has a predetermined value. Legal metrology ensures fair competition between packers and also consumer protection by laying down rules for prepackages in legislation.

OIML, the international organisation of legal metrology, is an intergovernmental organisation whose principal aim is to harmonise the regulations and metrological controls worldwide. The current scope of the recommendation OIML R 87 (Edition 2004) "Quantity of products in prepackages" [1] covers prepackages filled to the socalled "average principle". The document specifies:

a) the individual and average metrological requirements for prepackages labelled in predetermined quantities of weight, volume, length, area or counts, and

b) the sampling plans and procedures used to control production lots of prepackages by statistical means.

The OIML R 87 is currently under revision. A new feature under discussion for inclusion in the revised version is a new sampling scheme, a so-called multistep sampling plan. The major advantage of the multistep (or the stepwise) sampling plan over the single step procedure lies in the fact that less samples have to be controlled for confidence in terms of producer's as well as of consumer's risks. This procedure saves thus time both, the inspectors, but also for the packers, since less prepackages have to be opened and destroyed for control purposes.

\section{Metrological requirements}

OIML R 87 states that prepackages shall meet the following requirements (often also called the 3 packer's rules):

Average requirement: On average, the quantity of product in prepackages shall be at least equal to the nominal quantity $Q_{n o m}$. If the mean value is labeled $\mu$ this can be expressed by:

$$
\mu \geq Q_{\text {nom }}
$$

Requirement on small deficiencies: The quantity of product in any prepackage shall accurately reflect the nominal quantity, but tolerable deficiencies $T$ according table 1 are allowed. Only a small percentage of the prepackages are allowed to have a quantity between $\left(Q_{n o m}-2 T\right)$ and $\left(Q_{n o m}-T\right)$, called $T 1$ error. As an example, Eq. (2) states that only $2.5 \%$ of the packages have a $T l$ error:

a corresponding author to: hans-peter.vaterlaus@metas.ch 


$$
\sum_{i=1}^{N} I\left\{x_{i}<Q_{\text {nom }}-T\right\} \leq 0.025 N
$$

It has to be noted that the value of $2.5 \%$ is a parameter that can be selected. In certain countries this parameter is set to $2 \%$, making the condition on the number of deviating prepackages more stringent.

Requirement on large deviations: The last rule states that no prepackage shall have a quantity less than $Q_{n o m}-$ $2 T$ (referred to as $T 2$ error). In mathematical terms:

$$
\sum_{i=1}^{N} I\left\{x_{i}<Q_{n o m}-2 T\right\}=0
$$

Table 1 illustrates the current tolerable deficiencies for prepackages labelled by mass or volume according to OIML R 87 [1].

\begin{tabular}{|c|c|c|}
\hline $\begin{array}{c}\text { Nominal } \\
\text { quantity } \\
Q_{\text {nom }} \text { in g or } \mathrm{ml} \\
\end{array}$ & $\begin{array}{c}\text { Value of } T \\
\text { in \% of } \\
Q_{n o m} \\
\end{array}$ & $\begin{array}{l}\text { Value of } T \\
\text { in g or ml }\end{array}$ \\
\hline 0 to 50 & 9 & - \\
\hline 50 to 100 & - & 4.5 \\
\hline 100 to 200 & 4.5 & - \\
\hline 200 to 300 & - & 9 \\
\hline 300 to 500 & 3 & - \\
\hline 500 to 1000 & - & 15 \\
\hline 1'000 to 10 '000 & 1.5 & - \\
\hline $10^{\prime} 000$ to $15^{\prime} 000$ & - & 150 \\
\hline Above $15^{\prime} 000$ & 1 & - \\
\hline
\end{tabular}

Table 1. Tolerable deficiencies $T$.

\subsection{Reference test for metrological requirements and sampling procedure}

In most countries legal metrology officials conduct tests to determine if prepackages comply with requirements above. The tests are carried out by statistical means, based on random sampling of an hourly lot of production. From a production lot of size $N$ one selects a random sample of size $n$. The acceptance or rejection of the production lot is based on tests on the $n$ items of the sample. The statistical approach introduces a certain risk of rejecting wrongly a "good lot" (i.e. fulfilling the criteria). This risk is referred to a "producers risk". On the other hand there is also a certain risk to accept a "bad lot" (i.e. not fulfilling the criteria). This risk is called "consumer's risk" [2].

Average requirements for sampled lots: The probability of incorrectly rejecting an inspection lot satisfying Eq. (1) shall be no more than $0.5 \%$ (producer's risk or PR). The probability of correctly rejecting an inspection lot with an average quantity less than $Q_{n o m}-0.74 \sigma$ shall be at least $90 \%$, where $\sigma$ is the standard deviation of the net content of prepackages of the inspection lot (consumer's risk or CR).

Individual requirements for sampled lots: The probability of incorrectly rejecting a lot with $2.5 \%$ of the prepackages having $T 1$ or $T 2$ errors shall be smaller than $5 \%$ (producer's risk). The probability of correctly rejecting an inspection lot with $9 \%$ of the prepackages having $T 1$ or $T 2$ errors shall be at least $90 \%$ (consumer's risk).

On the basis of the given metrological requirements above and the specified producer's and consumer's risks, the associated statistical tests can be generated:

\subsection{Statistical principles of control by sampling}

Test of average requirement: Reject the lot if

$$
E_{a v e} / s+S C F \leq 0 \text { with } E_{\text {ave }}=\frac{1}{n} \sum_{i=1}^{n} E_{i}
$$

Here, $E_{\text {ave }}$ is the average of errors and $E_{i}$ are the individual prepackage errors defined by $E_{i}=Q_{i}-Q_{n o m}$, taking into account their signs, $n$ is the number of prepackages of the sample size, $s$ is the sample standard deviation of the individual errors, and $S C F$ is the Sample Correction Factor. The criteria in Eq. (4) guarantee that the probability of incorrectly rejecting an inspection lot is smaller than $0.5 \%$.

The $S C F$ for the identified lot size is calculated using the formula in Eq. (5):

$$
S C F=-\frac{t_{0.005, n-1}}{\sqrt{\frac{n(N-1)}{N-n}}} .
$$

Here, $t_{0.005, n-1}$ is the quantile of the Student's $t$ inverse cumulative distribution function with the two parameters, the probability $p=0.005$ and the degree of freedom $f=n-1$.

Test of individual requirements: The test for the two individual requirements is realized by performing statistics for the values of $n_{T 1}$ and $n_{T 2}$. These two statistics follow a multivariate hypergeometric distribution. The number $n_{T 1}$ is the maximum number of samples in the sample size being allowed for accepting the lot. The lot has to be rejected for $n_{T 2}$ being larger than zero. The corresponding criteria are also defined in Eqs. (2) and (3).

Under the assumption that only $2.5 \%$ of prepackages of the lot are allowed to have a $T 1$ error leads to the values of $n_{T 1}$ given in Table 2 for different lots sizes $N$.

Fulfilling the individual requirement in Table 2 guarantees that the probability of incorrectly rejecting an inspection lot is smaller than $5 \%(\mathrm{PR})$. This test also guarantees that a lot which has $9 \%$ of prepackages having a $T 1$ error will be correctly rejected with a 
probability of $90 \%(\mathrm{CR})$.

Table 2 shows that for lot sizes $N$ less than 32 the sample size $n$ is equal to 32 and a $100 \%$ inspection is needed. In this case the value of $S C F$ becomes 0 . This means the value of $E_{\text {ave }}$ cannot be lower than 0 otherwise the lot has to be rejected, which can be problematic for certain applications. This table also shows that for lot sizes above 500 the sample size $n$ will be over 80 . This high number is not only a burden to the packer at the time of inspection but also to the inspector, especially when destructive testing has to be applied. In order to avoid these inconveniences a new stepwise sampling plan is discussed for the future OIML R 87.

Table 2. Sampling plans for lot sizes $N$ and allowed number $n_{T I}$ of $T 1$ errors.

\begin{tabular}{|l|l|l|l|}
\hline $\begin{array}{l}\text { Inspection lot } \\
\text { size } N\end{array}$ & $\begin{array}{l}\text { Sample } \\
\text { size } n\end{array}$ & SCF & $\begin{array}{l}\text { Number of } \\
\text { allowed } \boldsymbol{T 1} \\
\text { errors } n_{\mathbf{T} 1}\end{array}$ \\
\hline Under 32 & 32 & 0 & 1 \\
\hline 60 & 50 & 0.16 & 2 \\
\hline 100 & 60 & 0.22 & 3 \\
\hline 200 & 64 & 0.27 & 3 \\
\hline 500 & 81 & 0.27 & 4 \\
\hline 800 & 82 & 0.28 & 4 \\
\hline 1000 & 96 & 0.26 & 5 \\
\hline 1500 and larger & 98 & 0.26 & 5 \\
\hline
\end{tabular}

\section{Multistep sampling procedure}

The multistep sampling procedure is especially appropriate for controlling so-called "low-risk" prepackages and high hourly production rates.

The principle is to start with a limited number of measurements and proceed with additional measurements only if the test is not conclusive. At each step there is an acceptance criteria for the lot.

Taking an example of a packer producing 50'000 prepackages per hour Table 3 shows this multistep procedure with at maximum of 7 steps. At each step a maximum number of packages allowed to have $T 1$ errors is defined (last column). If the number of items with a $T 1$ error is below or equal to this figure, the lot is accepted. If the number of packages with $T 1$ error exceeds the allowed value, more measurements are carried out, until the full sample size - 130 items in the present case - is reached.
Table 3. Multistep sampling plan for lot size $N=50^{\prime} 000$ and allowed number $n_{T 1}$ of $T 1$ errors

\begin{tabular}{|l|l|l|l|}
\hline $\begin{array}{l}\text { Step } \\
\text { number }\end{array}$ & $\begin{array}{l}\text { Sample size } n \\
\text { in each step }\end{array}$ & SCF & $\begin{array}{l}\text { Number of } \\
\text { allowed } \boldsymbol{T 1} \\
\text { errors } n_{T 1}\end{array}$ \\
\hline 1 & 40 & 0.43 & 0 \\
\hline 2 & 55 & 0.36 & 1 \\
\hline 3 & 70 & 0.32 & 2 \\
\hline 4 & 90 & 0.28 & 3 \\
\hline 5 & 105 & 0.26 & 4 \\
\hline 6 & 115 & 0.24 & 5 \\
\hline 7 & 130 & 0.23 & 6 \\
\hline
\end{tabular}

Potentially it is thus possible to accept the lot after only 40 measurements which is a considerable less than the 98 measurements foreseen by one-step sampling plan (cf Table 2). Obviously, this can save time and money.

\section{Conclusion}

Control of quantity of product in prepackages is important in view of fair trade, competitive markets and protection of consumers. Traditionally such controls are performed by using a single step sampling scheme. We present a new sampling scheme that ensures the same level of confidence in terms of consumer's and producer's risk. The new scheme is a multi-step sampling scheme, in which potentially less packages must be measured.

The OIML recommendation R87 - a standard document for the testing of prepackage - is currently under revision. For its new version, a multistep sampling procedure as possible means to test prepackage is under discussion. This is particularly interesting for high volume production of prepacked goods.

\section{References}

1. OIML R 87 Quantity of product in prepackages, International Organisation of Legal Metrology (2004)

2. C H Sim, Requirements and process control for quantity of product in prepackages, Metrologica 44 (2007) 